\title{
TOTAL QUALITY MANAGEMENT: KONSEP PENINGKATAN MUTU PENDIDIKAN
}

\author{
Hasnadi \\ Manajemen Pendidikan Islam, STAIN Teungku Dirundeng Meulaboh, Aceh, Indonesia \\ Email: hasnadi@staindirundeng.ac.id
}

\begin{abstract}
Abstrak
Pemerintah Indonesia telah berupaya dengan menerapkan beberapa program unggulan untuk meningkatkan mutu pendidikan. Akan tetapi, beragamnya tantangan yang dihadapi oleh sekolah berpengaruh terhadap belum optimalnya pencapaian mutu pendidikan. Tujuan penulisan artikel ini adalah untuk menganalisa dan mendeskripsikan tentang konsep Total Quality Management (TQM) sebagai salah satu upaya meningkatkan mutu pendidikan. Penulisan artikel ini menggunakan metode kualitatif dengan pendekatan literature review. Konsep TQM merupakan salah satu konsep yang dapat diterapkan untuk meningkatkan mutu pendidikan. Dalam menerapkan konsep TQM pada pendidikan, maka perlu memperhatikan beberapa aspek, yaitu: (1) fokus pada pengguna lulusan, (2) obsesi terhadap mutu, (3) pendekatan ilmiah, (4) kerjasama tim, (5) memiliki komitmen jangka panjang dan berkelanjutan, (6) upaya perbaikan secara terus menerus, (7) melakukan pendidikan dan pelatihan, (8) persamaan persepsi dan tujuan, (9) memiliki budaya organisasi yang bebas dan terkendali, dan (10) adanya keterlibatan dan pemberdayaan sumber daya manusia. Semua aspek TQM ini harus berorientasi pada sistem manajemen pendidikan, perilaku warga sekolah, fokus pada pelayanan secara optimal dalam rangka memenuhi kebutuhan, keinginan dan keperluan pengguna lulusan (stakeholders).
\end{abstract}

Kata Kunci : Total Quality Management, Mutu, Pendidikan

\begin{abstract}
The Indonesian government has made efforts to implement numbers of excellent programs to improve the quality of education. However, the variety of challenges faced by schools effect the lack of optimal competition in the quality of education. The purpose of this article is to analyze and describe the concept of Total Quality Management (TQM) as an effort to improve the quality of education. This article uses a qualitative method with a literature review approach. The TQM concept is one of the concepts that can be applied to improve the quality of education. In applying the TQM concept to education, it is necessary to pay attention to several aspects, namely: (1) focus on graduate users, (2) obsession with quality, (3) scientific approach, (4) teamwork, (5) having a long-term commitment and sustainable, (6) continuous improvement efforts, (7) conducting education and training, (8) common perceptions and goals, (9) having a free and controlled organizational culture, and (10) engaging and empowering human resources. All aspects of TQM must be oriented to the education management system, the behavior of school members, focus on optimal service in order to meet the needs, and desires of the stakeholders.
\end{abstract}

Key Words : Total Quality Management, Quality, Education

\section{PENDAHULUAN}

Sumber daya manusia (SDM) merupakan komponen penting dan berpengaruh terhadap pencapaian tujuan pendidikan [1]. Rendahnya kualitas SDM menjadi suatu dasar dari masalah sehingga dapat menghambat pembangunan dan pembangunan ekonomi nasional [2]. Dimensi pembangunan pendidikan sangat luas yang meliputi aspek sosial, budaya, politik dan ekonomi [3]. Mutu pendidikan merupakan faktor penting dalam pembangunan negara dan meningkatkan daya saing secara global ([4], [5]). Pendidikan yang berkualitas merupakan sasaran setiap negara dalam mendukung kemajuan pembangunan dan peningkatan kualitas sumber daya manusia. Hal penting bagi masa depan suatu negara dan semua warga negara adalah menyiapkan lulusan 
yang berkualitas, sehingga mampu menguasai perkembangan teknologi dan mampu bersaing secara global [6].

Input pendidikan (sumber daya manusia, finansial, peserta didik dan lain-lain) yang berasal dari lingkungan akan menempuh proses di lembaga pendidikan, sehingga menghasilkan output yang pada akhirnya akan kembali kepada masyarakat dan lingkungan. Kualitas input, proses dan output pendidikan dapat mempengaruhi kualitas atau mutu pendidikan. Hal ini menunjukkan bahwa kualitas atau mutu pendidikan mengacu pada batasan waktu tertentu.

Pemerintah Indonesia telah berupaya melakukan berbagai macam upaya dalam rangka peningkatan mutu pendidikan. Namun, pendidikan di Indonesia belum dapat berfungsi secara optimal sehingga dapat menyebabkan rendahnya kualitas mutu pendidikan di Indonesia. Pendidikan di Indonesia memiliki beberapa permasalahan yang berkaitan dengan kualitas pendidikan di antaranya merupakan keterbatasan akses pendidikan [7], jumlah guru yang belum merata [8], rendahnya kualitas guru dan relevansi pendidikan, manajemen pendidikan masih lemah, minimnya biaya pendidikan [9], terbatasnya sarana dan prasarana Pendidikan [10], kemiskinan [11], kurang memadai sarana dan prasarana Pendidikan [12], serta rendahnya budaya literasi di Indonesia [13], rendahnya kesejahteraan guru dan guru yang kurang memahami kurikulum 2013 sehingga proses pembelajaran kurang optimal [14].

Penyusunan Indeks Mutu Pendidikan (IMP) perlu dilakukan sebagai alat ukur terhadap mutu pendidikan pada setiap jenjang pendidikan [15]. Mutu lembaga pendidikan dapat dirancang melalui program-program sekolah yang menjadi keunggulan sekolah (brand) untuk diterapkan di sekolah. Program unggulan sekolah dapat memberikan dampak pada peningkatan mutu pendidikan [16].

Semua permasalahan tentang komponenkomponen dan indikator mutu pendidikan berdampak pada rendahnya mutu lulusan. Salah satu strategi untuk meningkatkan mutu pendidikan di Indonesia yaitu dengan menerapkan konsep TQM (Total Quality Management). Konsep TQM yang berfokus pada pelanggan atau pengguna lulusan diyakini sebagai salah satu kunci keberhasilan untuk mencapai kesuksesan dalam mengelola pendidikan. TQM merupakan sebuah konsep manajemen sekolah dalam penyelenggaraan pendidikan dan diharapkan mampu memberikan perubahan yang lebih baik sesuai dengan perkembangan, tuntutan dan dinamika masyarakat dalam menyikapi permasalahan manajemen pendidikan di sekolah [17].

Penerapan TQM di lembaga pendidikan dapat dilihat dari tanggung jawab seluruh warga sekolah terhadap mutu pendidikan, sehingga semua pihak seperti komite sekolah, kepala sekolah, kepala administrasi, guru, siswa terlibat dalam proses akademik di lembaga pendidikan dan memahami tujuan pendidikan yang ingin dicapai [18].

TQM merupakan suatu pendekatan yang strategis, sistematis dan praktis dalam menyelenggarakan suatu organisasi dengan mengutamakan kepentingan pengguna untuk meningkatkan dan mengendalikan mutu ([19], [20]). Setiap tenaga kependidikan dan guru bertanggung jawab untuk mewujudkan pengajaran yang bermutu yang pada akhirnya dapat meningkatkan mutu pendidikan [21].

Tujuan penulisan artikel ini adalah untuk mereview dan menganalisis tentang peningkatan mutu pendidikan dengan 
menerapkan konsep Total Quality Management. Artikel ini sangat menarik dibaca oleh seluruh praktisi pendidikan dalam rangka meningkatkan mutu pendidikan. Hasil analisis dan pembahasan dalam artikel ini diharapkan dapat bermanfaat bagi seluruh praktisi pendidikan dalam meningkatkan mutu pendidikan.

\section{METODE}

Penulisan artikel ini menggunakan pendekatan literature review. Literature review merupakan uraian teori, hasil penelitian dan temuan yang didapatkan dari berbagai sumber untuk dijadikan sebagai landasan kegiatan penelitian. Literature review dapat memberikan informasi kepada pembaca atau peneliti tentang hasil-hasil penelitian yang berkaitan dengan penelitian yang dilakukan, menghubungkan penelitian dengan literatur-literatur yang ada serta mengisi celah-celah penelitian sebelumnya [22].

Penulis menganalisis dan mendeskripsikan tentang konsep TQM sebagai salah satu upaya meningkatkan mutu pendidikan melalui beberapa teori dan hasil penelitian dari berbagai sumber, sehingga hasil penulisan artikel ini menarik untuk dibaca. Data dan informasi terkait fokus penulisan dalam artikel ini bersumber dari buku-buku dan jurnal-jurnal penelitian nasional maupun internasional. Analisis data dan informasi dilakukan secara mendalam dengan cara merangkum tentang fokus masalah yang dibahas dalam artikel ini.

\section{HASIL DAN PEMBAHASAN}

TQM merupakan model manajemen yang pertama kali dikembangkan di bidang manufaktur dan berfokus pada pengendalian mutu. TQM mengalami evolusi dan mengalami diversifikasi untuk aplikasi di bidang manufaktur, industri jasa, kesehatan, dan bidang pendidikan.
TQM merupakan sistem manajemen yang melalui kegiatan perbaikan secara berkesinambungan dengan melibatkan semua tenaga pendidikan dan tenaga kependidikan pada setiap level jabatan untuk mencapai kualitas yang baik serta berorientasi pada kepuasan pengguna lulusan.

Penerapan TQM pada lembaga pendidikan didasarkan pada peningkatan mutu yang harus dilakukan oleh semua personel sekolah secara terpadu dan berkesinambungan untuk memenuhi kebutuhan para pelanggan atau pengguna lulusan pada masa sekarang dan masa akan datang. Lembaga pendidikan sebagai unit pelayanan jasa akan melayani pada aspek; (1) pelanggan internal yang terdiri dari guru, pustakawan, laboran, teknisi, dan tenaga administrasi; (2) pelanggan eksternal terdiri atas pelanggan primer (siswa), pelanggan sekunder (orang tua, pemerintah dan masyarakat) dan pelanggan tersier (pemakai/penerima lulusan) [19]. Pelanggan dalam dunia pendidikan dibagi menjadi 3 kelompok, yaitu pelanggan primer (terlibat langsung seperti pelajar), pelanggan sekunder (penunjang pendidikan seperti orang tua), dan pelanggan tersier (terlibat secara tidak langsung tetapi memiliki peran penting dalam pendidikan, seperti pegawai, masyarakat, dan pemerintah) [23].

TQM merupakan sistem manajemen mutu yang terkait dengan perbaikan berkelanjutan dalam peningkatan mutu pendidikan dari berbagai aspek secara keberlanjutan. Kualitas pendidikan dapat dilihat dari kebutuhan dan kepuasan pelanggan. Penerapan TQM pada lembaga pendidikan dilakukan sebagai salah satu upaya untuk meningkatkan mutu pendidikan pada satuan pendidikan [2].

TQM berfokus pada suatu sistem pencapaian tujuan lembaga pendidikan 
yang dimulai dari proses perbaikan mutu untuk mengurangi kesalahan dalam menghasilkan kualitas lulusan sebagai harapan para pelanggan atau pengguna lulusan. Prosedur dan strategi sebagai komponen TQM dalam peningkatan mutu pendidikan diuraikan secara rinci berikut ini.

\section{Fokus pada pengguna lulusan}

Pengguna lulusan pada suatu lembaga pendidikan terdiri dari pelanggan internal dan pelanggan eksternal. Pelanggan internal berpengaruh terhadap kualitas manusia, proses dan lingkungan yang berhubungan dengan kualitas lulusan. Pelanggan eksternal berpengaruh terhadap kualitas lulusan suatu lembaga pendidikan.

Karakteristik lembaga pendidikan yang berfokus pada pelanggan adalah; (1) visi, misi, komitmen dan suasana lembaga pendidikan, (2) menyesuaikan diri dengan pengguna lulusan, (3) keinginan untuk mengidentifikasi dan mengatasi permasalahan pengguna lulusan, (4) memanfaatkan informasi dari pengguna lulusan, (5) mendekati pengguna lulusan, (6) memiliki kemampuan dan pemberdayaan personel sekolah, dan (7) perbaikan kualitas proses dan kualitas lulusan secara terus menerus [24]. Ketujuh karakteristik di atas berfokus pada pengguna lulusan dapat dilakukan dengan cara mengevaluasi diri secara internal dan eksternal.

\section{Obsesi terhadap kualitas}

Penerapan TQM pada lembaga pendidikan harus terobsesi terhadap mutu pendidikan yang sesuai dengan kebutuhan pelanggan secara internal dan eksternal. Penjaminan mutu internal meliputi; (1) kebijakan dan prosedur penjaminan mutu, pemantauan terhadap program secara berkala, (3) evaluasi personel lembaga pendidikan, (4) kualitas guru/ staf, (5) sumber belajar, (6) sistem informasi, (7) informasi publik. Penjaminan mutu eksternal meliputi; (1) Penerapan prosedur, (2) pengembangan proses, (3) kriteria terhadap keputusan, (4) proses sesuai dengan tujuan yang ingin dicapai, (5) pelaporan, (6) tindak lanjut, (7) peninjauan terhadap pelaksanaan secara berkala, dan (8) analisis seluruh sistem [25]. Obsesi terhadap mutu pada lembaga pendidikan diharapkan dapat melebihi dari mutu yang diharapkan oleh pengguna lulusan.

\section{Pendekatan Ilmiah}

Penerapan TQM pada lembaga pendidikan membutuhkan pendekatan ilmiah untuk mendesain tugas setiap personel lembaga pendidikan dan mendesain proses pengambilan keputusan serta pemecahan masalah yang berhubungan dengan pencapaian tujuan pendidikan yang berkualitas. Langkah-langkah untuk melakukan pendekatan ilmiah dalam TQM adalah; pengumpulan data, mengidentifikasi sumber dari penyebab suatu masalah, menghasilkan solusi yang tepat, dan merencanakan untuk melakukan perubahan ke arah yang lebih baik.

\section{Komitmen jangka panjang}

Komitmen jangka panjang dan berkelanjutan dibutuhkan dalam penerapan TQM dan harus menjadi sebuah budaya pada lembaga pendidikan untuk mencapai mutu. Komitmen seluruh personel lembaga pendidikan tentang pentingnya mutu dan melakukan upaya-uapaya peningkatan mutu sangat mempengaruhi keberhasilan lembaga pendidikan dalam meningkatkan mutu pendidikan. Komitmen staf dan organisasi berpengaruh terhadap kinerja staf dan kinerja manajemen mutu [26]. Oleh karena itu, komitmen untuk menjaga mutu dan meningkatkan mutu pendidikan sangat dibutuhkan secara jangka panjang.

\section{Teamwork}

Teamwork sangat diperlukan dalam menerapkan TQM pada lembaga 
pendidikan. Oleh karena itu, teamwork dan kemitraan perlu dijalin dan dibina antar personel lembaga pendidikan, orang tua siswa, lembaga-lembaga pemerintah dan swasta, serta masyarakat di lingkungan lembaga pendidikan, sehingga berdampak pada efektivitas dan kepuasan tim [27]. Keberhasilan teamwork dapat dilakukan dengan cara; kepemimpinan, kepercayaan, saling membutuhkan, saling melengkapi, menggunakan bahasa komunikasi yang baik, kemampuan pemecahan masalah, kemampuan mengelola konflik, dan evaluasi yang berkelanjutan.

Lembaga pendidikan perlu memastikan kondisi dan lingkungan untuk mendukung teamwork dalam bekerja sehingga keamanan psikologis dapat berkembang dan menyelesaikan konflik, mengurangi kesalahan, memastikan keselamatan dan meningkatkan kinerja [34]. Terdapat beberapa strategi untuk mengoptimalkan teamwork, yaitu; (1) bekerja melebihi standar yang ditentukan, (2) membangun kerjasama dan proses tim secara efektif, (3) mengelola masalah pengembangan teamwork, dan (4) meningkatkan kompetensi sumber daya manusia [27].

\section{Perbaikan sistem secara berkelanjutan}

Lembaga pendidikan yang menerapkan TQM akan melakukan inovasi secara berkelanjutan, melakukan perbaikan secara terarah, dan mengalami siklus perbaikan secara terus menerus. Perbaikan sistem secara berkelanjutan dapat dilakukan dengan cara menentukan sumber masalah, mencari solusi dari masalah, implementasi pemecahan masalah secara efektif dan efisien, melakukan evaluasi, membuat standarisasi mutu dan pengulangan proses.

Perbaikan sistem secara berkelanjutan memiliki dampak positif terhadap manajemen organisasi yang memiliki pedoman dan program kerja secara berkelanjutan dalam pengelolaan organisasi [28]. Upaya perbaikan dan peningkatan mutu dapat dilakukan melalui supervisi pendidikan yang dilakukan secara demokratis, komprehensif, konstruktif, objektif, dan berkesinambungan melalui pendekatan kolegial, klinis, individual dan artistik yang sesuai dengan kondisi institusi pendidikan [29]. Oleh karena itu, sistem yang ada perlu diperbaiki secara berkelanjutan sehingga mutu pendidikan yang dicapai dapat meningkat dan sesuai dengan kebutuhan pengguna lulusan.

\section{Pendidikan dan pelatihan}

Lembaga pendidikan yang menerapkan TQM akan memberikan kesempatan bagi seluruh personil sekolah untuk mengikuti pendidikan dan pelatihan yang merupakan sebagai faktor fundamental. Pendidikan dan pelatihan merupakan faktor dasar bagi setiap personel lembaga pendidikan untuk meningkatkan keterampilan teknisnya yang pada akhirnya dapat meningkatkan mutu pendidikan. Salah satu bentuk pengembangan SDM pendidikan adalah melalui pendidikan dan pelatihan, misalnya melalui off the job dan on the job training [30].

\section{Budaya bebas dan terkendali}

Penerapan konsep TQM pada lembaga pendidikan memiliki budaya lembaga pendidikan yang melibatkan dan memberdayakan personel sekolah dalam pengambilan keputusan serta pemecahan masalah. Keterlibatan personel sekolah dalam perencanaan dan pengambilan keputusan dapat meningkatkan rasa memiliki dan tanggungjawab personel sekolah terhadap pencapaian tujuan dan mempengaruhi kualitas lembaga pendidikan. Keterlibatan karyawan dalam pengambilan keputusan menjadi kekuatan dalam mengambil peluang dalam bisnis yang dapat secara signifikan mempengaruhi hasil produktivitas [31]. 


\section{Persamaan persepsi dan tujuan}

Persamaan persepsi dan tujuan lembaga pendidikan perlu dilakukan agar penerapan TQM dapat diterapkan dengan baik. Pimpinan lembaga pendidikan perlu mengarahkan seluruh staf kepada tujuan yang sama tentang usaha-usaha yang dilakukan. Persepsi personel lembaga pendidikan memberikan kontribusi secara signifikan terhadap komitmen organisasi dalam mencapai tujuan [32].

\section{Keterlibatan dan pemberdayaan sumber daya manusia}

Keterlibatan dan pemberdayaan sumber daya manusia pada lembaga pendidikan sangat penting dilakukan dalam penerapan TQM. Keterlibatan personel sekolah dapat bermanfaat untuk meningkatkan keputusan, rencana, dan perbaikan yang lebih baik dan lebih efektif. Keterlibatan personel sekolah juga bermanfaat untuk meningkatkan rasa memiliki dan tanggungjawab atas keputusan yang melibatkan personel yang harus melaksanakannya. Keterlibatan karyawan berpengaruh terhadap kesiapan organisasi dalammenghadapi perubahan [33].

Komponen-komponen TQM di atas menunjukkan bahwa konsep TQM pada dasarnya berorientasi pada sistem manajemen, perilaku staf, fokus organisasi dan proses-proses pengadaan pelayanan sehingga lembaga pendidikan yang menyediakan pelayanan dapat menghasilkan lulusan yang lebih bermutu dan pelayanan yang lebih efektif untuk memenuhi kebutuhan, keinginan dan keperluan pelanggan atau pengguna lulusan.

Penjaminan mutu pendidikan di sekolah dapat dilakukan melalui standarisasi, sertifikasi, uji kompetensi, penilaian kinerja, dan evaluasi mutu internal atau evaluasi diri [34]. Akreditasi sekolah, salah satu bentuk akuntabilitas publik yang mengarah pada pendidikan berkualitas. Pelaksanaan akreditasi diharapkan dapat mendorong atau membentuk suasana yang kondusif bagi perkembangan pendidikan, memberikan arahan untuk melakukan evaluasi diri yang berkelanjutan dan menjadi pendorong untuk terus menerus mencapai mutu yang diinginkan yang secara tidak langsung dapat menjamin mutu Pendidikan [35]. Peningkatan mutu pendidikan di Indonesia hendaknya dilakukan secara bersama antara pemerintah, sekolah dan masyarakat yang memiliki peran yang sangat penting dalam rangka pencapaian mutu Pendidikan [36].

\section{SIMPULAN}

TQM merupakan suatu usaha yang dilakukan melalui pendekatan secara maksimal melalui kegiatan-kegiatan yang dilakukan secara berkelanjutan terhadap manusia, jasa, produk yang dihasilkan dan lingkungan yang diciptakan berdasarkan mutu, bekerja secara tim, produktivitas, prestasi dan kepuasan pelanggan. Lembaga pendidikan perlu menerapkan pendekatan yang integratif dan objektif dalam manajemen mutu. Komitmen dari seluruh staf dan semua stakeholder terhadap perbaikan adalah aspek utama dari TQM. Bagi kepala sekolah, pengawas dan pimpinan lembaga pendidikan agar dapat menerapkan komponen-komponen konsep TQM dalam meningkatkan mutu pendidikan.

\section{DAFTAR PUSTAKA}

[1] H. Hasnadi, "Perencanaan Sumber Daya Manusia Pendidikan," Bidayah Stud. Ilmu-Ilmu Keislam., vol. 10, no. 2, pp. 141-148, 2019.

[2] P. Y. A. Dewi dan K. H. Primayana, "Peranan Total Quality Management (TQM) di Sekolah Dasar," $J$. Penjaminan Mutu, vol. 5, no. 2, pp. 226-236, 2019.

[3] S. Suryana, "Permasalahan Mutu Pendidikan dalam Perspektif 
Pembangunan Pendidikan," Edukasi, vol. 14, no. 1, pp. 1-12, 2020.

[4] B. Tarman, "Innovation and Education," Res. Soc. Sci. Technol., vol. 1, no. 1, pp. 76-97, 2016.

[5] T. Budiharso dan B. Tarman, "Improving Quality Education through Better Working Conditions of Academic Institutes," J. Ethn. Cult. Stud., vol. 7, no. 1, pp. 99115, 2020.

[6] H. Kanematsu and D. M. Barry, STEM and ICT education in intelligent environments. Springer, 2016.

[7] M. Murdiono, S. Suyato, dan I. Arpannudin, "Strategi Penguatan Nasionalisme Perbatasan Indonesia," JPK (Jurnal Pancasila dan Kewarganegaraan), vol. 5, no. 2, pp. 34-43, 2020.

[8] Y. A. Priambodo dan S. Y. J. Prasetyo, "Pemetaan Penyebaran Guru di Provinsi Banten dengan Menggunakan Metode Spatial Clustering K-Means (Studi kasus: Wilayah Provinsi Banten)," Indones. J. Comput. Model., vol. 1, no. 1, pp. 18-27, 2018.

[9] S. Subardi, "Jaminan Mutu Pendidikan Guru," Sustain. J. Kaji. Mutu Pendidik., vol. 2, no. 2, pp. 198-211, 2019.

[10] R. Pahlevi, A. Imron, dan D. E. Kusumaningrum, "Manajemen Saranan dan Prasarana untuk Meningkatkan Mutu Pembelajaran," Manaj. Pendidik., vol. 25, no. 1, pp. 88-94, 2016.

[11] I. N. Wijana dan M. Suhardi, "Pemerataan Akses Pendidikan Bagi Anak Putus Sekolah di Provinsi Nusa Tenggara Barat," Alignment J. Adm. Educ. Manag., vol. 1, no. 1, pp. 11-23, 2018.

[12] Y. Istislami, "Permasalahan Mutu Pendidikan Indonesia," J. Lentera
(Jurnal Pendidik. dan Pengajaran Bhs. Indones., vol. 3, no. 2, pp. 276283, 2020.

[13] H. Hasnadi, "Membangun Budaya Literasi Informasi pada Perguruan Tinggi," in Prosiding SEMDIUNAYA (Seminar Nasional Multi Disiplin Ilmu UNAYA), 2019, vol. 3, no. 1, pp. 610-620.

[14] A. Rachman, "Implementasi Kebijakan Kepala Madrasah dalam Meningkatkan Kinerja Guru," $J M$ TBI J. Manaj. dan Tarbiyatul Islam, vol. 1, no. 1, pp. 94-99, 2020.

[15] F. A. Awwaliyah dan I. M. Arcana, "Pembentukan Indeks Mutu Pendidikan (IMP) di Indonesia Tahun 2018 dan Faktor yang Memengaruhinya," in Seminar Nasional Official Statistics, 2020, vol. 2020, no. 1, pp. 385-396.

[16] M. Hayudiyani, B. R. Saputra, M. A. Adha, dan N. S. Ariyanti, "Strategi Kepala Sekolah Meningkatkan Mutu Pendidikan melalui Program Unggulan Sekolah," J. Akuntabilitas Manaj. Pendidik., vol. 8, no. 1, pp. 89-95, 2020.

[17] N. Indana, "Implementasi Total Quality Management (TQM) dalam Meningkatkan Mutu Pendidikan: (Studi Kasus di MTs Salafiyah Syafi'iyah Tebuireng)," Al-Idaroh J. Stud. Manaj. Pendidik. Islam, vol. 1, no. 1, pp. 62-86, 2017.

[18] M. H. Nasution, "Manajemen Mutu Terpadu (MMT) dalam Pendidikan Islam," Al-Muaddib J. Ilmu-Ilmu Sos. Dan Keislam., vol. 4, no. 2, pp. 228-248, 2019.

[19] S. Minarti, Manajemen Sekolah. Jogjakarta: Ar-Russ Media, 2011.

[20] F. Ismail, "Implementasi Total Quality Management (TQM) di Lembaga Pendidikan," J. Ilm. Iqra', vol. 10, no. 2, 2018.

[21] F. A. Siregar, "Produktivitas 
Penerapan Total Quality Management," Idarah (Jurnal Pendidik. dan Kependidikan), vol. 2, no. 2, pp. 74-91, 2018.

[22] J. W. Creswell, "Research Design Pendekatan Kualitatif, Kuantitatif, dan Mixed," Yogyakarta: pustaka pelajar, 2010.

[23] S. Suhermanto dan A. Anshari, "Implementasi TQM terhadap Mutu Institusi dalam Lembaga Pendidikan," Al-Tanzim J. Manaj. Pendidik. Islam, vol. 2, no. 1, pp. 107-113, 2018.

[24] D. L. Goetsch dan S. B. Davis, "Introduction to Total Quality," Qual. Funct. Deploy., pp. 245-279, 1997.

[25] M. Fadhli, "Sistem Penjaminan Mutu Internal dan Ekstenal pada Lembaga Pendidikan Tinggi," $A L$ TANZIM J. Manaj. Pendidik. Islam, vol. 4, no. 2, pp. 53-65, 2020.

$$
\text { R. Indriyati, "Pengaruh }
$$

Kepemimpinan, Budaya Organisasi dan Komitmen Organisasi terhadap Kinerja Manajemen Mutu (Studi pada AKPELNI Semarang)," Media Ekon. dan Manaj., vol. 33, no. 1, 2018.

[27] T. A. O'Neill and E. Salas, "Creating High Performance Teamwork in Organizations," Hum. Resour. Manag. Rev., vol. 28, no. 4, pp. 325-331, 2018.

[28] D. Perawironegoro, H. Widodo, S. Suluri, dan Z. M. R. Harahap, "Penyusunan Program Kerja untuk Perbaikan Berkelanjutan Organisasi Santri Darul Arqam Patean Kendal Jawa Tengah," in Seminar Nasional Hasil Pengabdian Kepada Masyarakat, 2019, pp. 117-126.

[29] H. Hasnadi, "The Importance of Supervision Implementation in Educational Institution," J. Dedik. Pendidik., vol. 5, no. 1, pp. 1-10,
2021.

[30] I. Fathurrochman, "Pengembangan Kompetensi Pegawai Aparatur Sipil Negara (ASN) Sekolah Tinggi Agama Islam Negeri (STAIN) Curup melalui Metode Pendidikan dan Pelatihan," Manajer Pendidik., vol. 11, no. 2, 2017.

[31] S. E. Farmen Rizal, "Peranan Kepemimpinan dan Keterlibatan Karyawan terhadap Pengambilan Keputusan dan Dampaknya terhadap Produktivitas PT. Sumber Kreasi Fumiko," Maj. Manaj. dan Bisnis Ganesha, vol. 1, no. 2, pp. 59-80, 2017.

[32] U. D. A. Wibowo, "Peran Persepsi tentang Lingkungan Kerja Psikososial terhadap Komitmen Organisasional pada Lembaga Pendidikan Islam," UNISIA, vol. 37, no. 82, pp. 81-87, 2018.

[33] H. Susyanto, "Pengaruh Kepemimpinan, Keterlibatan Karyawan dan Kepuasan Kerja terhadap Kesiapan untuk Berubah dalam Menghadapi Perubahan Organisasi," J. Ekon. Bisnis, dan Akunt., vol. 21, no. 1, 2019.

[34] K. Kusnandi, "Konsep Dasar dan Strategi Penjaminan Mutu Pendidikan: Sebagai Review Kebijakan Mutu Pendidikan," Indones. J. Educ. Manag. Adm. Rev., vol. 1, no. 2, pp. 107-118, 2018.

[35] A. A. R. Awaludin, "Akreditasi Sekolah sebagai Suatu Upaya Penjaminan Mutu Pendidikan di Indonesia," SAP (Susunan Artik. Pendidikan), vol. 2, no. 1, 2017.

[36] I. N. T. Astawa, "Memahami Peran Masyarakat dan Pemerintah dalam Kemajuan Mutu Pendidikan di Indonesia," J. Penjaminan Mutu, vol. 3, no. 2, pp. 197-205, 2017. 